\title{
Fabrication of Ultrafine Amorphous Pd-Ni-P Nanoparticles Supported on Carbon Nanotubes as an Effective Catalyst for Electro-oxidation of Methanol
}

\author{
Ming Zhao*, Yuan Ji, and Ning Zhong
}

School of Chemical Engineering, China University of Mining and Technology, No1, Daxue Road, Xuzhou, 221116, P. R. China

*Email: ming815zhao@163.com

doi: $10.20964 / 2016.12 .61$

Received: 21 September 2016 / Accepted: 18 October 2016 / Published: 10 November 2016

We presented the fabrication of ultrafine amorphous Pd-Ni-P nanoparticles with a mean size of $3 \mathrm{~nm}$. During the reduction, the use of borane tert-butylamine complex was crucial for the small particle formation. Notably, the addition of strong reducing reagent does not lead to the formation of crystallized Pd or Ni-P phases at all. The amorphous Pd-Ni-P composite was proved to be the most efficient catalyst in comparison with $\mathrm{Pd}, \mathrm{Pd}-\mathrm{Ni}$, and even its crystalline counterpart for the electrochemical oxidation of methanol in alkaline medium. Moreover, compared with Vulcan XC-72, carbon nanotubes was found to be a more effective support with which 1.8 times high specific activity was achieved.

Keywords: palladium; amorphous materials; nanoparticles; carbon nanotube; electro-oxidation

\section{FULL TEXT}

(C) 2016 The Authors. Published by ESG (www.electrochemsci.org). This article is an open access article distributed under the terms and conditions of the Creative Commons Attribution license (http://creativecommons.org/licenses/by/4.0/). 